\title{
Combination of Doxorubicin with Gemcitabine-Incorporated G- Quadruplex Aptamer Showed Synergistic and Selective Anticancer Effect in Breast Cancer Cells ${ }^{\text {s }}$
}

\author{
Mili Joshi, Jong-Soo Choi, Jae-Won Park, and Kyung-Oh Doh* \\ Department of Physiology, College of Medicine, Yeungnam University, Daegu 42415, Republic of Korea
}

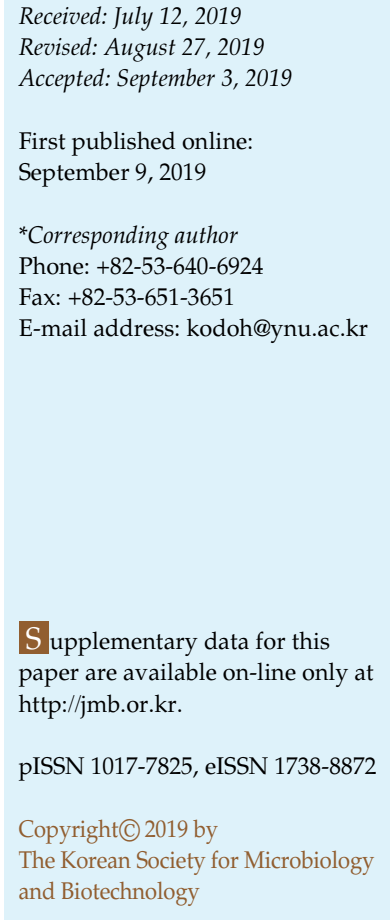

Doxorubicin (DOX) is one of the most effective anticancer agents used for the treatment of multiple cancers; however, its use is limited by its short half-life and adverse drug reactions, especially cardiotoxicity. In this study, we found that the conjugate of DOX with APTA12 (Gemcitabine incorporated G-quadruplex aptamer) was significantly more cancer selective and cytotoxic than DOX. The conjugate had an affinity for nucleolin, with higher uptake and retention into the cancer cells than those of DOX. Further, it was localized to the nucleus, which is the target site of DOX. Owing to its mechanism of action, DOX has the ability to intercalate into the nucleotides thus making it a suitable drug to form a conjugate with cancer selective aptamers such as APTA12. The conjugation can lead to selectively accumulate in the cancer cells thus decreasing its potential nonspecific as well as cardiotoxic side effects. The aim of this study was to prepare a conjugate of DOX with APTA12 and assess the chemotherapeutic properties of the conjugate specific to cancer cells. The DOX-APTA12 conjugate was prepared by incubation and its cytotoxicity in MCF-10A (non-cancerous mammary cells) and MDA-MB-231 (breast cancer cells) was assessed. The results indicate that DOX-APTA12 conjugate is a potential option for chemotherapy especially for nucleolin expressing breast cancer with reduced doxorubicin associated side effects.

Keywords: G-quadruplex aptamer, doxorubicin, gemcitabine, selective anticancer therapy, breast cancer

\section{Introduction}

Doxorubicin (DOX) has an anthracycline structure and shows its cytotoxic activity by intercalating with the DNA structure in the nucleus. DOX, with its planar anthracycline ring, is known to preferentially bind with double-stranded $5^{\prime}-$ GC-3' or 5'-CG-3' sequences [1]. It is one of the most effective chemotherapeutic agents used in the treatment of multiple cancers, such as breast cancer, cervical cancer, liver cancer, lung cancer, lymphoma, multiple myeloma, head and neck cancer, and soft tissue sarcoma. However, its use has been challenging due to numerous side effects, notably cardiotoxicity, especially congestive cardiomyopathy [2]. Congestive cardiomyopathy has been reported in onethird to one-half of elderly patients with B-cell lymphoma treated with DOX in combination with other anticancer drugs [3].

Aptamers are synthetic, single-stranded RNA or DNA molecules which are short, usually 20 to 60 nucleotides, and can bind to various molecular targets by secondary or tertiary structures with high specificity and affinity [4]. Aptamers are also called chemical antibodies and have several advantages such as smaller size, lower immunogenicity, higher stability and flexible structure [5]. AS1411, developed as a nucleolin aptamer, showed excellent tolerability and promising cancer-selective uptake, but its progress was limited by its high renal clearance and low potency $[6,7]$. APTA12, a gemcitabine (GEM) incorporated G-quadruplex aptamer, was developed by a single substitution of the guanine residue at position 14 of the 
AS1411 aptamer sequence (5'-GGT GGT GGT GGT TGT GGT GGT GGT GG-3') with gemcitabine phosphoramidite, thereby changing the sequence to $5^{\prime}$-GGT GGT GGT GGT TZT GGT GGT GGT GG-3'(Z- Gemcitabine) [8]. This modified aptamer has been found to have a high affinity for nucleolin [8] which is overexpressed in most cancer cells [9-12].

GEM has been found to be one of the most effective drugs for the treatment of pancreatic cancer, but several studies also suggest its potential as a chemotherapeutic agent for metastatic breast cancer as well [13, 14]. GEM triphosphate competes with deoxycytidine triphosphate for incorporation into DNA thus forming an abnormal base which leads to cell death [15]. However, it has its own limitations such as low molecular weight, high hydrophilicity, nucleoside transporter dependence and easy degradation by cytidine deaminase leading to poor penetration into the tumor cells [14, 16-19].

GEM in combination with DOX has been reported to have benefitted approximately $78 \%$ of the patients with metastatic breast cancer [13]. In addition, it has been reported that aptamer-drug conjugate improves the targeted delivery and therapeutic effect of anticancer agents in prostate cancer, breast cancer, colorectal cancer, pancreatic cancer and lymphoblastic leukemia [20-23]. Previous studies have reported a physical conjugate between DOX and A10 RNA aptamer that binds to PSMA protein on the surface of prostate cancer cells and targets cancer cells with high specificity [24].

In this study, APTA12 and DOX were formulated into a conjugate that has the potential to show improved cancer selectivity and better cytotoxicity while retaining its affinity to nucleolin in breast cancer cells.

\section{Materials and Methods}

\section{Cell Culture}

MCF-7 and MDA-MB-231 cells (human breast cancer cell lines) were obtained from Korean Cell Line Bank and were maintained in RPMI 1640 supplemented with 10\% fetal bovine serum (FBS), $0.1 \% 2 \mathrm{mM}$ L-glutamine, 100 units $/ \mathrm{ml}$ penicillin, and $100 \mu \mathrm{g} / \mathrm{ml}$ streptomycin, in a humidified incubator, maintained at $37^{\circ} \mathrm{C}$ with $5 \% \mathrm{CO}_{2}$. MCF-10A (immortal human mammary epithelial cell line) cells were obtained from ATCC and maintained in MEGM bullet kit (Lonza, Switzerland). The cell culture reagents, including FBS, were purchased from WelGENE (Korea).

\section{Preparation of Doxorubicin Intercalated APTA12 Conjugate (APTA12-DOX)}

The aptamer APTA12, used in this study was obtained from
AptaBio (Korea) and DOX was purchased from Sigma. APTA12 was dissolved in $10 \mathrm{mM}$ potassium phosphate buffer, $\mathrm{pH} 7.4$ to obtain a final concentration of $200 \mu \mathrm{M}$, and was heated at $94^{\circ} \mathrm{C}$ for $5 \mathrm{~min}$ and annealed at room temperature. Heat annealed aptamers were then incubated with DOX at room temperature for 1 hour to form the conjugate and then stored at $4^{\circ} \mathrm{C}$. One molar equivalence of DOX to aptamer was used unless otherwise mentioned.

Conjugate formation was assessed by incubating a fixed concentration of DOX with an increasing molar ratio of APTA12 $(0,0.04,0.08,0.16,0.31,0.63,1.25,2.5,5)$, and changes in native fluorescence spectrum were observed.

Fluorescence spectra were observed by a microplate reader (SpectraMax, Molecular Devices, USA) at $485 \mathrm{~nm}$ excitation and $530 \mathrm{~nm}$ emission with cut off at $515 \mathrm{~nm}$.

\section{Cell Viability Assay}

The cells (2,000/well) were seeded in 96-well culture plates for $24 \mathrm{~h}$ before treatment with DOX, APTA12, GEM, co-treatment with DOX and APTA12-DOX conjugate for $2 \mathrm{~h}$ followed by media change. For the cell viability assay, $30 \mu \mathrm{g}$ of Methylthiazolyldiphenyltetrazolium bromide (MTT) dissolved in $20 \mu$ of PBS (Phosphate Buffer Saline) was added to each well along with $80 \mu$ of fresh medium and incubated at $37^{\circ} \mathrm{C}$ for $3 \mathrm{~h}$. The formazan crystals produced were completely dissolved in DMSO by shaking at $450 \mathrm{rpm}$ for $3 \mathrm{~min}$, and absorbance was measured at $550 \mathrm{~nm}$ on a microplate reader (Tecan, Tecan group AG, Switzerland). Untreated cells were used as OD (Optical Density) controls.

Cell viability was calculated using the following equation:

Cell viability $(\%)=$ OD value of sample/OD value of control * 100

\section{Cellular Uptake of APTA12-DOX by Flow Cytometry}

The cells $(100,000 /$ well) were seeded in 6-well culture plates for $24 \mathrm{~h}$ before treatment with DOX, APTA12, and APTA12-DOX for $2 \mathrm{~h}$ followed by media change. After treatment with DOX for the required period, cells were washed twice with ice-cold PBS and harvested by treating with trypsin/EDTA solution (Gibco). The harvested cells were centrifuged at 2,000 rpm for $5 \mathrm{~min}$ at $4^{\circ} \mathrm{C}$, washed with ice-cold PBS $(500 \mu \mathrm{l})$. The cells were suspended in $500 \mu \mathrm{l}$ of $1 \%$ paraformaldehyde (PFA) and fluorescein-conjugated APTA12 (FAM-APTA12) was analyzed by FACS using Canto II flow cytometry instrument (Becton-Dickinson, USA).

\section{Competition Assay}

Fluorescein-conjugated APTA12 (FAM-APTA12) was obtained from APTAbio. Cells (40,000/well) were seeded on glass slides in 24-well plates overnight and then incubated with AS1411 $(5 \mu \mathrm{M})$ for $2 \mathrm{~h}$. $1.5 \mu \mathrm{M}$ of FAM-APTA12-DOX conjugate was added to treated cells and incubated for $30 \mathrm{~min}$. The cells were fixed with $4 \%$ PFA and mounted for observation under Leica TCS SP2 spectral scanning confocal microscope (Leica Microsystems, Germany).

\section{Confocal Imaging and Cell Localization}

Cells $(40,000 /$ well $)$ were seeded on glass plates in 24 -well plates 
overnight and then incubated with FAM-APTA12-DOX conjugate at $37^{\circ} \mathrm{C}$ for $1 \mathrm{~h}$ and $2 \mathrm{~h}$. The cells were then incubated for $4 \mathrm{~h}$ and $22 \mathrm{~h}$ after treatment to observe the time-dependent localization of DOX and FAM-APTA12. The cells were then fixed with 4\% PFA for 10-15 min and again washed with cold PBS. The nucleus was stained with TO-PRO-3 in PBS and incubated at $37^{\circ} \mathrm{C}$ for $15 \mathrm{~min}$. The slide was prepared with a drop of DAKO, dried, and visualized under a confocal microscope (Leica Microsystems).

\section{Cell Cycle Analysis}

Cells $(100,000 /$ well) were seeded in 6-well culture plates for $24 \mathrm{~h}$ before treatment with APTA12, APTA12-DOX, DOX, GEM, and DOX+GEM for $2 \mathrm{~h}$ followed by media change. After further $72 \mathrm{~h}$ incubation, cells were washed twice with ice-cold PBS and harvested by treating with trypsin/EDTA solution (Gibco). The harvested cells were centrifuged at 2,000 rpm for $5 \mathrm{~min}$ at $4^{\circ} \mathrm{C}$, washed with ice-cold PBS (500 $\mu \mathrm{l})$ and fixed with $70 \%$ cold ethanol for $15 \mathrm{~min}$ on ice. After washing again with PBS, the cells were stained with FxCycle PI/RNase staining solution (Invitrogen) for 15-30 $\mathrm{min}$ at room temperature (r.t.) and analyzed by using FACSCanto II flow cytometry instrument (Becton-Dickinson, USA).

\section{Statistical Analysis}

Statistical comparisons were performed by using Student's $t$ test or one-way ANOVA with Tukey's test. Results are presented as mean \pm SD for data from triplicate experiments. All computational analyses were carried out using Prism 7 (GraphPad) and for all tests, $p<0.05$ was considered significant.

\section{Results}

\section{Formation and Stability of APTA12-DOX Conjugate}

Fluorescence spectroscopy was used to examine the binding of DOX to APTA12. Sequential decrease in the native fluorescence spectrum of DOX was observed when DOX was incubated with an increasing molar ratio of APTA12. The dissociation constant of APTA12-DOX physical conjugate was derived from the Hill plot which suggested the spontaneous formation of the stable physical conjugate.

DOX structure has a planar anthracycline ring which can slide into the G-quartet structure to form a physical conjugate. The decrease in fluorescence due to intercalation of DOX within APTA12 was found to be maximal at approximately 1:1 molar equivalence of DOX to the aptamer, suggesting that DOX indeed forms a physical conjugate with APTA12 (Fig. S1).

\section{Effect of APTA12-DOX Intercalation on Cell Cytotoxicity}

The cytotoxicity of APTA12-DOX conjugate was examined in MCF-10A cells (non-cancerous mammary cells) and

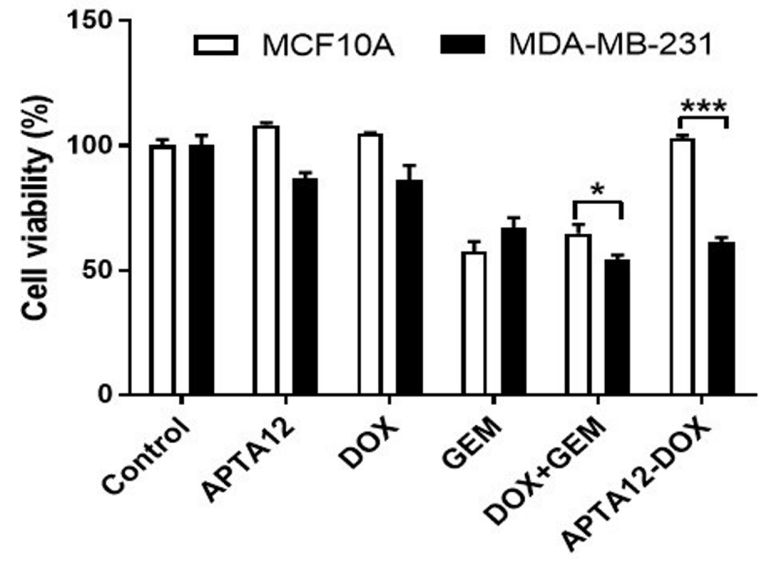

Fig. 1. Cancer selective cytotoxicity of APTA12-DOX.

MCF-10A (non-cancerous mammary cells) and MDA-MB-231 (breast cancer cells) cells were treated with $0.1 \mu \mathrm{M}$ of APTA12-DOX, DOX + GEM, DOX, APTA12, and GEM for $2 \mathrm{~h}$ and cell viability was measured after $72 \mathrm{~h}$ incubation in fresh medium. *Indicates significant difference $\left({ }^{*} p<0.05,{ }^{* * *} p<0.001\right)$. Data represents the average of three individual experiments.

MDA-MB-231 cells (breast cancer cells). Conjugated APTA12-DOX showed significant cytotoxicity in MDAMB-231 cells at the concentration of $0.1 \mu \mathrm{M}$, but the conjugate did not show any cytotoxicity in MCF-10A cells. APTA12 and DOX individually showed low cytotoxicity in MDA-MB-231 cells. However, treatment of cells with gemcitabine and co-treatment with gemcitabine and DOX at the same concentration showed significant cytotoxicity in both cells (Fig. 1).

\section{Cellular Uptake of APTA12-DOX and Competition Assay with AS1411}

In order to demonstrate the difference of cellular uptake of APTA12-DOX in normal and cancer cells, fluorescencelabeled APTA12 (FAM-APTA12) was used. The fluorescence in MDA-MB-231 cells was found to be significantly higher than in MCF-10A cells suggesting that APTA12-DOX was selectively internalized into cancer cells (Fig. 2A). Subsequently, the uptake of FAM-APTA12-DOX in MDAMB-231 cells was assessed to observe whether the uptake of the conjugated APTA12-DOX is nucleolin-dependent, while using AS1411 pre-treatment as a nucleolin binding competitor. The uptake of FAM-APTA12-DOX was significantly decreased in AS1411 pre-treated cells (Fig. 2B).

\section{Cellular Localization of APTA12-DOX}

The localization of APTA12-DOX conjugate in MDA-MB231 cells was observed by confocal microscopy. Although a 
A
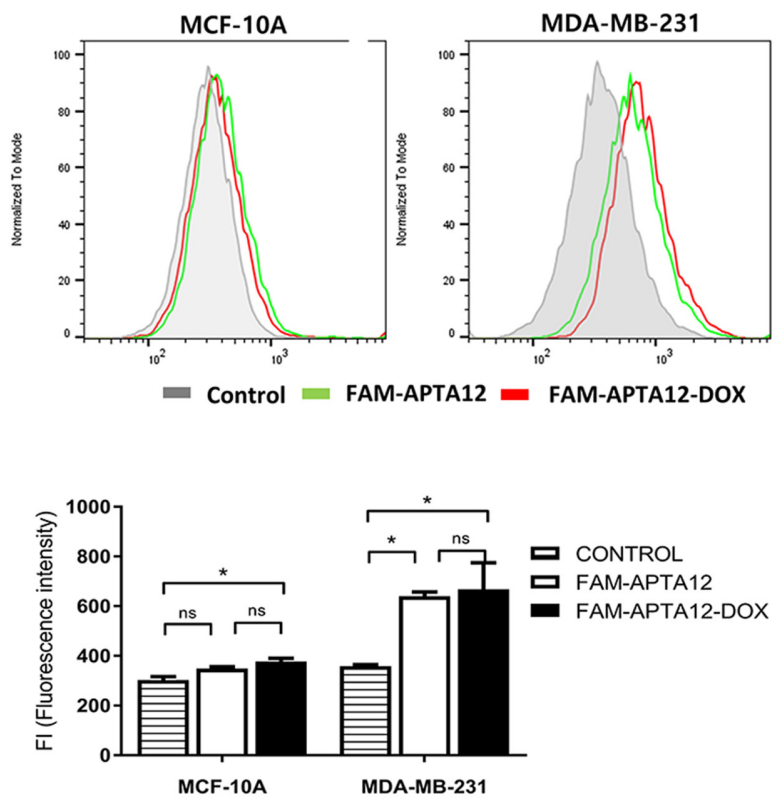

B
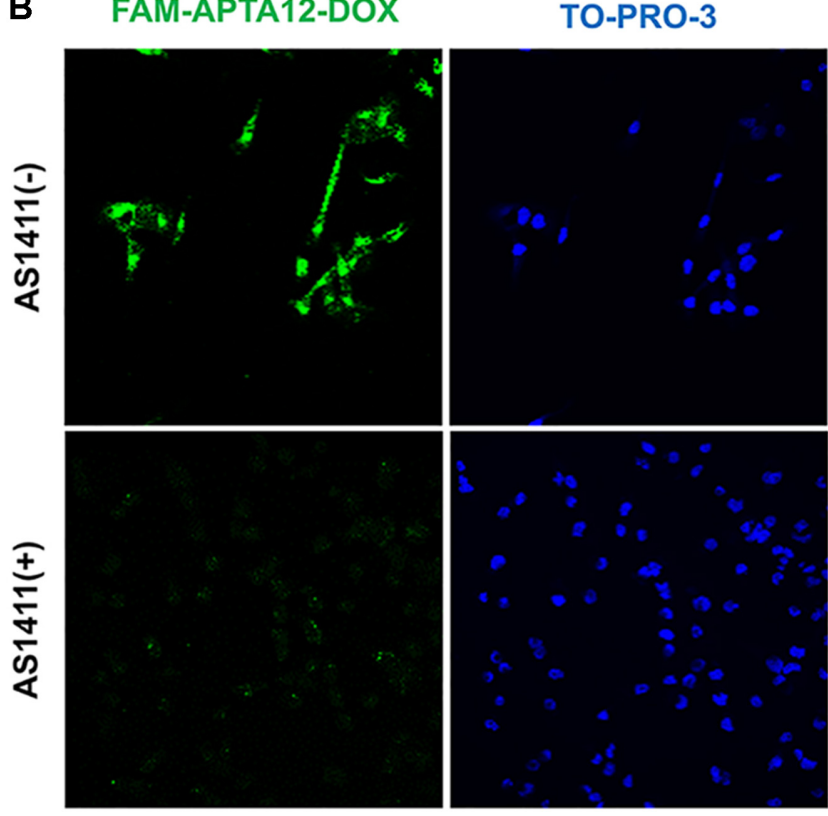

Fig. 2. Cancer selective uptake of APTA12-DOX by nucleolin. (A) Flow cytometry analysis of MCF-10A cells and MDA-MB-231 cells. Cells were incubated with FAM-APTA12 and FAM-APTA12DOX for $2 \mathrm{~h}$ and immediately analyzed by flow cytometry. (B) Confocal images of MDA-MB-231 cells. Cells were pretreated with $5 \mu \mathrm{M}$ of AS1411 as a nucleolin competitor for $2 \mathrm{~h}$ and then incubated with $1.5 \mu \mathrm{M}$ FAM-APTA12-DOX for $0.5 \mathrm{~h}$. ${ }^{*}$ Indicates significant difference $\left({ }^{*} p<0.05\right)$. ns; not significant.

weak fluorescence of FAM-APTA12 was detected at $1 \mathrm{~h}$ after treatment with APTA12-DOX conjugate, we observed increased uptake of the conjugate at $2 \mathrm{~h}$ after the treatment.
DOX fluorescence was observed in and around the nucleus, and FAM-APTA12 fluorescence was located on the periphery of the nucleus. After $4 \mathrm{~h}$ incubation, DOX fluorescence had significantly increased in the nucleus, suggesting that more DOX was released from the physical conjugate with APTA12. The fluorescence of APTA12 and DOX was retained by the cells for more than $24 \mathrm{~h}$ after the treatment (Fig. 3).

\section{Cell Cycle Analysis}

To investigate the synergistic cytotoxicity of DOX and GEM in cells treated with APTA12-DOX physical conjugate, cell cycle was analyzed by flow cytometry. Cell cycle parameters were compared between untreated MDA-MB231 cells and cells treated for $2 \mathrm{~h}$ with APTA12, APTA12DOX, DOX, GEM and DOX + GEM, and then incubated for $72 \mathrm{~h}$. Cell cycle of MDA-MB-231 cells after APTA12-DOX and DOX + GEM treatment was similar compared to other treatment groups. The results showed significant cell cycle arrest in G2/M phase by DOX treatment and in S and G2/ $M$ phase arrest by GEM treatment (Fig. 4).

\section{Discussion}

DOX intercalated into APTA12 to form a stable physical conjugate that selectively inhibited cancer cell growth compared to cells treated with either APTA12, DOX, GEM or GEM + DOX co-treatment. This selective cytotoxicity is derived from increased uptake of APTA12 by nucleolin, which is abundant in cancer cells compared to normal cells. This observation is concordant with a previous study which showed that the presence of GEM in APTA12 contributed to lower IC50 value, while retaining its cancer selective property [8].

At an excitation wavelength of $480 \mathrm{~nm}$, fluorescence spectra of DOX $(20 \mu \mathrm{M})$ with increasing molar ratios of the aptamer showed maximal binding affinity at approximately 1:1 molar equivalence of DOX to aptamer. This observation concords with a study which reports fluorescence quenching as evidence of PSMA aptamer DOX conjugate [24]. As a result, itOur results showed that DOX is able to intercalate into the G-quadruplex structure of APTA12 to form a conjugate.

The advantage of APTA12-DOX conjugate is in its ability to show synergistic cancer selective cytotoxic effect at a low concentration within a short treatment time.

The synergistic effect of DOX and GEM on cytotoxicity is well known when administered concurrently $[13,25,26]$. The cytotoxicity of APTA12-DOX was similar to DOX + 


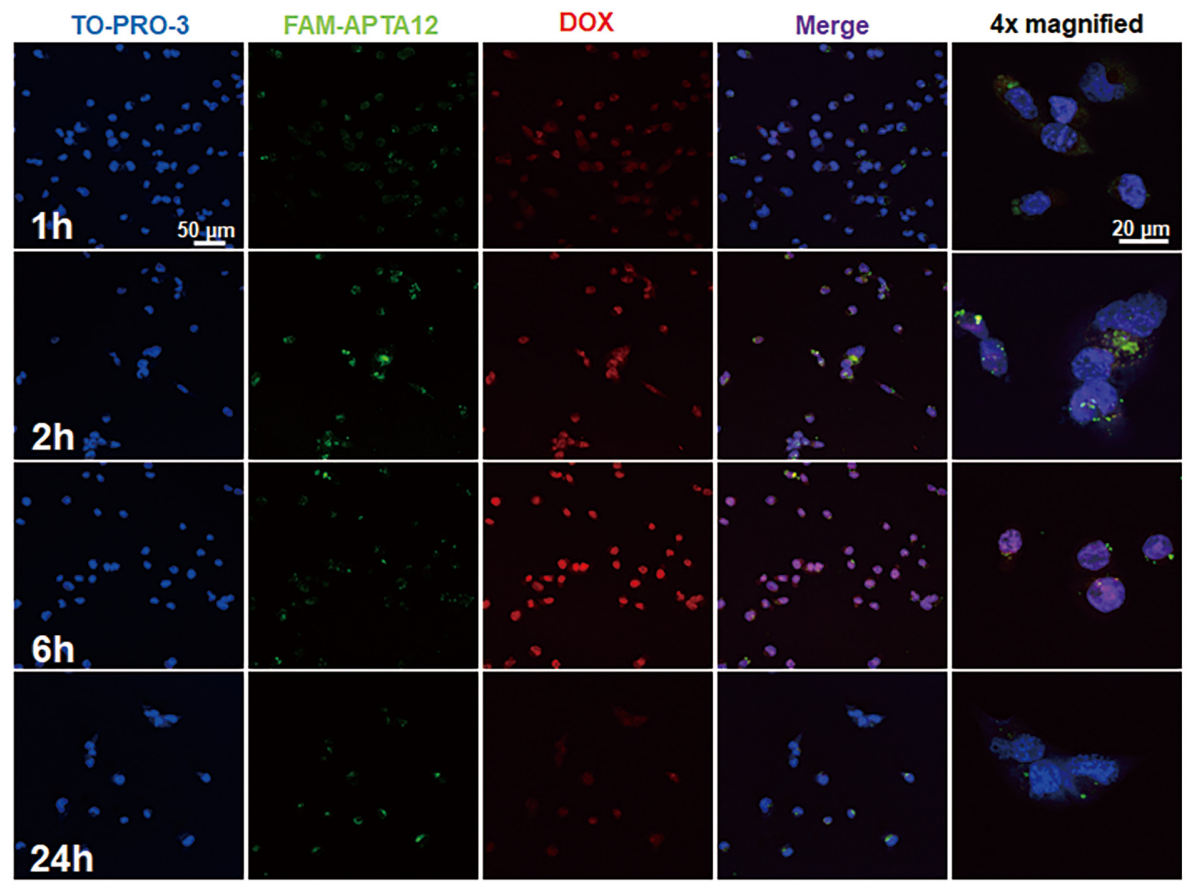

Fig. 3. Cellular localization of APTA12-DOX in MDA-MB-231 cells.

Cells were treated with FAM-APTA12-DOX $(1.5 \mu \mathrm{M})$ for 1 or $2 \mathrm{~h}$. Fluorescence was observed under confocal microscope immediately after incubation ( $1 \mathrm{~h}$ and $2 \mathrm{~h}$ ) or after further incubation with fresh medium for $4 \mathrm{~h}(6 \mathrm{~h})$ or $22 \mathrm{~h}(24 \mathrm{~h})$.

GEM and the synergistic cytotoxic effect of APTA12-DOX might be due to the presence of GEM component in APTA12.

DOX causes cell cycle arrest in G2/M phase [27], and GEM arrests the cell cycle at S and G2/M phase [28]. Previous studies have reported a significant increase in the proportion of $S$ phase in the cells treated with G-rich oligonucleotides (GROs) [29]. Cell cycle distribution in MDA-MB-231 cells after APTA12-DOX and DOX + GEM treatments was similar compared to other treatment groups, suggesting the major role of GEM in the synergistic cytotoxicity of APTA12-DOX.

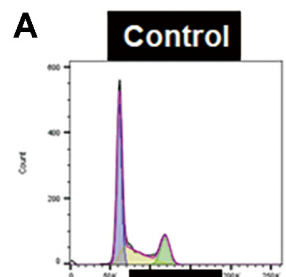

DOX

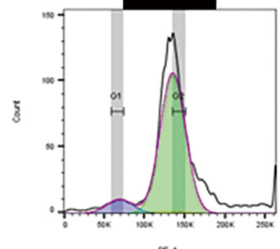

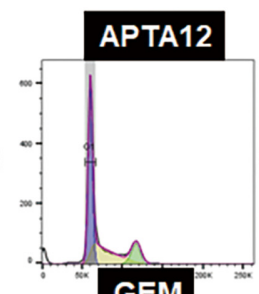

GEM

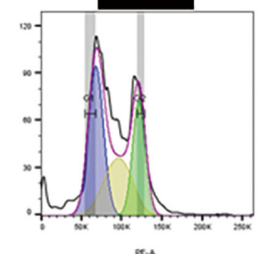

APTA12-DOX

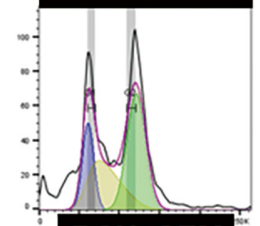

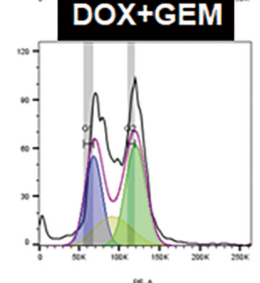

B

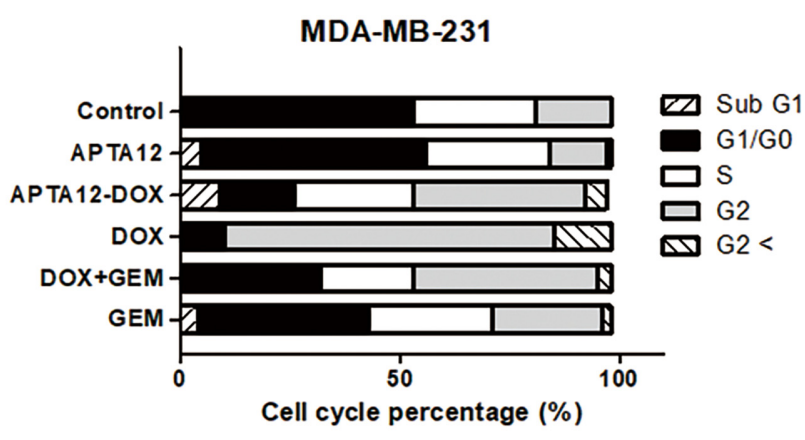

Fig. 4. Cell cycle analysis of APTA12-DOX.

(A) PI staining. Cell cycle was analyzed in MDA-MB-231 cells after $2 \mathrm{~h}$ treatment with $0.2 \mu \mathrm{M}$ of APTA12, APTA12-DOX conjugate, DOX, DOX + GEM and GEM followed by $72 \mathrm{~h}$ incubation in fresh medium. (B) Histogram of cell cycle analysis. 
The cellular uptake of APTA12-DOX in MDA-MB-231 cells was found to be significantly higher than that by MCF-10A cells. As previously reported, cancer cells express more nucleolin on their cell surface [10, 12, 30], indicating that the higher cellular uptake of APTA12-DOX by MDAMB-231 cells is nucleolin dependent.

This was further confirmed by performing a competitive assay. MDA-MB-231 cells pre-treated with AS1411, as a competitor of nucleolin, displayed decreased uptake of the APTA12-DOX which confirmed that it specifically targeted cell surface nucleolin. The nucleolin was saturated by AS1411, making it less available for FAM-APTA12-DOX to interact and enter the cells. Hence, the uptake of APTA12DOX in cells was proportional to the availability of nucleolin, especially on the cell surface. Even though nucleolin is one of the major proteins in the nucleus, it is also expressed in cell membrane and cytoplasm and is an important ligand binding protein associated with cancer. A previous study has suggested that nucleolin is overexpressed in cancer cells compared to normal cells making it a potential target for selective cancer therapy [30]. The results showed that most of the conjugate entered the cells via nucleolin where they were degraded and released GEM and DOX which are responsible for synergistic cytotoxic activity.

In conclusion, we showed that DOX could effectively intercalate into APTA12, and the conjugate showed better cytotoxicity at a much lower concentration. The conjugate retained the cancer selectivity by nucleolin binding attributes and demonstrated selective uptake into the target cell. In summary, the results herein indicate that DOX intercalation into APTA12 makes a stable conjugate which shows synergistic and selective anti-cancer effects in breast cancer cells.

\section{Acknowledgments}

This work was supported by a grant from the Chunma Medical Research Foundation, Korea, 2016.

\section{Conflict of Interest}

The authors have no financial conflicts of interest to declare.

\section{References}

1. Chaires JB, Herrera JE, Waring MJ. 1990. Preferential binding of daunomycin to 5'TACG and 5'TAGC sequences revealed by footprinting titration experiments. Biochemistry 29: 61456153.

2. Singal PK, Siveski-Iliskovic N, Hill M, Thomas TP, Li T. 1995. Combination therapy with probucol prevents adriamycininduced cardiomyopathy. J. Mol. Cell. Cardiol. 27: 1055-1063.

3. Fridrik MA, Jaeger U, Petzer A, Willenbacher W, Keil F, Lang A, et al. 2016. Cardiotoxicity with rituximab, cyclophosphamide, non-pegylated liposomal doxorubicin, vincristine and prednisolone compared to rituximab, cyclophosphamide, doxorubicin, vincristine, and prednisolone in frontline treatment of patients with diffuse large B-cell lymphoma: A randomised phase-III study from the Austrian Cancer Drug Therapy Working Group [Arbeitsgemeinschaft Medikamentöse Tumortherapie AGMT](NHL-14). Eur. J. Cancer 58: 112-121.

4. Bates PJ, Laber DA, Miller DM, Thomas SD, Trent JO. 2009. Discovery and development of the G-rich oligonucleotide AS1411 as a novel treatment for cancer. Exp. Mol. Pathol. 86: 151-164.

5. Gold L. 1995. Oligonucleotides as research, diagnostic, and therapeutic agents. J. Biol. Chem. 270: 13581-13584.

6. Bates PJ, Reyes-Reyes EM, Malik MT, Murphy EM, O'toole MG, Trent JO. 2017. G-quadruplex oligonucleotide AS1411 as a cancer-targeting agent: Uses and mechanisms. Biochim. Biophys. Acta Gen. Subj. 1861: 1414-1428.

7. Rosenberg JE, Bambury RM, Van Allen EM, Drabkin HA, Lara PN, Harzstark AL, et al. 2014. A phase II trial of AS1411 (a novel nucleolin-targeted DNA aptamer) in metastatic renal cell carcinoma. Invest. New Drugs 32: 178-187.

8. Park JY, Cho YL, Chae JR, Moon SH, Cho WG, Choi YJ, et al. 2018. Gemcitabine-incorporated G-Quadruplex aptamer for targeted drug delivery into pancreas cancer. Mol. Ther. Nucleic Acids 12: 543-553.

9. Reyes-Reyes EM, Teng Y, Bates PJ. 2010. A new paradigm for aptamer therapeutic AS1411 action: uptake by macropinocytosis and its stimulation by a nucleolin-dependent mechanism. Cancer Res. 70: 817-829.

10. Fonseca NA, Rodrigues AS, Rodrigues-Santos P, Alves V, Gregorio AC, Valerio-Fernandes A, et al. 2015. Nucleolin overexpression in breast cancer cell sub-populations with different stem-like phenotype enables targeted intracellular delivery of synergistic drug combination. Biomaterials 69: 7688.

11. Qiu W, Zhou F, Zhang Q, Sun X, Shi X, Liang Y, et al. 2013. Overexpression of nucleolin and different expression sites both related to the prognosis of gastric cancer. APMIS 121: 919-925.

12. Berger CM, Gaume X, Bouvet P. 2015. The roles of nucleolin subcellular localization in cancer. Biochimie 113: 78-85.

13. Rivera E, Valero V, Arun B, Royce M, Adinin R, Hoelzer K, et al. 2003. Phase II study of pegylated liposomal doxorubicin in combination with gemcitabine in patients with metastatic breast cancer. J. Clin. Oncol. 21: 3249-3254. 
14. Ueno H, Kiyosawa K, Kaniwa N. 2007. Pharmacogenomics of gemcitabine: can genetic studies lead to tailor-made therapy? Br. J. Cancer 97: 145-151.

15. Huang P, Chubb S, Hertel LW, Grindey GB, Plunkett W. 1991. Action of 2', 2'-difluorodeoxycytidine on DNA synthesis. Cancer Res. 51: 6110-6117.

16. Maréchal R, Mackey JR, Lai R, Demetter P, Peeters M, Polus $\mathrm{M}$, et al. 2009. Human equilibrative nucleoside transporter 1 and human concentrative nucleoside transporter 3 predict survival after adjuvant gemcitabine therapy in resected pancreatic adenocarcinoma. Clin. Cancer Res. 15: 2913-2919.

17. Mackey JR, Mani RS, Selner M, Mowles D, Young JD, Belt JA, et al. 1998. Functional nucleoside transporters are required for gemcitabine influx and manifestation of toxicity in cancer cell lines. Cancer Res. 58: 4349-4357.

18. Vrignaud S, Benoit J-P, Saulnier P. 2011. Strategies for the nanoencapsulation of hydrophilic molecules in polymerbased nanoparticles. Biomaterials 32: 8593-8604.

19. Amrutkar M, Gladhaug I. 2017. Pancreatic cancer chemoresistance to gemcitabine. 9(11). pii: E157. doi: 10.3390/ cancers9110157.

20. Li L, Xiang D, Shigdar S, Yang W, Li Q, Lin J, et al. 2014. Epithelial cell adhesion molecule aptamer functionalized PLGA-lecithin-curcumin-PEG nanoparticles for targeted drug delivery to human colorectal adenocarcinoma cells. Int. J. Nanomedicine 9: 1083-1096.

21. Zhou W, Zhou Y, Wu J, Liu Z, Zhao H, Liu J, et al. 2014. Aptamer-nanoparticle bioconjugates enhance intracellular delivery of vinorelbine to breast cancer cells. J. Drug Target. 22: 57-66.

22. Ray P, Cheek MA, Sharaf ML, Li N, Ellington AD, Sullenger BA, et al. 2012. Aptamer-mediated delivery of chemotherapy to pancreatic cancer cells. Nucleic Acid Ther. 22: 295-305.
23. Shahidi-Hamedani N, Shier WT, Moghadam Ariaee F, Abnous K, Ramezani M. 2013. Targeted gene delivery with noncovalent electrostatic conjugates of sgc-8c aptamer and polyethylenimine. J. Gene. Med. 15: 261-269

24. Bagalkot V, Farokhzad OC, Langer R, Jon S. 2006. An aptamer-doxorubicin physical conjugate as a novel targeted drug-delivery platform. Angew. Chem. Int. Ed. Engl. 45: 81498152.

25. Vogus DR, Evans MA, Pusuluri A, Barajas A, Zhang M, Krishnan V, et al. 2017. A hyaluronic acid conjugate engineered to synergistically and sequentially deliver gemcitabine and doxorubicin to treat triple negative breast cancer. J. Control. Release 267: 191-202.

26. Vogus DR, Pusuluri A, Chen R, Mitragotri S. 2018. Schedule dependent synergy of gemcitabine and doxorubicin: Improvement of in vitro efficacy and lack of in vitro-in vivo correlation. Bioeng. Trans. Med. 3: 49-57.

27. Ling Y-H, El-Naggar AK, Priebe W, Perez-Soler R. 1996. Cell cycle-dependent cytotoxicity, G2/M phase arrest, and disruption of p34cdc2/cyclin B1 activity induced by doxorubicin in synchronized P388 cells. Mol. Pharmacol. 49: 832-841.

28. Matthews DJ, Yakes $\mathrm{M}$, Chen J, Tadano M, Bornheim L, Clary DO, et al. 2007. Pharmacological abrogation of S-phase checkpoint enhances the anti-tumor activity of gemcitabine in vivo. Cell Cycle 6: 104-110.

29. Xu X, Hamhouyia F, Thomas SD, Burke TJ, Girvan AC, McGregor WG, et al. 2001. Inhibition of DNA replication and induction of $\mathrm{S}$ phase cell cycle arrest by G-rich oligonucleotides. J. Biol. Chem. 276: 43221-43230.

30. Hovanessian AG, Soundaramourty C, El Khoury D, Nondier I, Svab J, Krust B. 2010. Surface expressed nucleolin is constantly induced in tumor cells to mediate calciumdependent ligand internalization. PLoS One 5: e15787. 